\title{
СОЦИАЛЬНО-ЭКОНОМИЧЕСКОЕ ПОЛОЖЕНИЕ СУБЪЕКТОВ ЦЕНТРАЛЬНОГО ФЕДЕРАЛЬНОГО ОКРУГА В КОНТЕКСТЕ КОНКУРЕНТНЫХ ПОЗИЦИЙ
}

\section{SOCIO-ECONOMIC SITUATION OF THE SUBJECTS OF THE CENTRAL FEDERAL DISTRICT IN THE CONTEXT OF COMPETITIVE POSITIONS}

V. Scherbakov

A. Dubrovsky

Summary. The article reveals the regularities of the socio-economic development of subjects as components of the potential for sustainable growth in the region, and also substantiates the methodological foundations of a comprehensive assessment and monitoring of the competitive positions of the regions of the Central Federal District of the Russian Federation in terms of finding the reserves of sustainable growth. The hypothesis of the study consists in substantiating, taking into account scientific and practical experience, the assumption that an assessment of the potential for the socio-economic development of a region allows us to identify directions for increasing the stability of the economic system and its competitive positions.

A number of economic and social indicators were used to assess the level of development of the regions. The calculation of the integral parameters of economic and social development was carried out by means of standardization according to the average Russian value. The priority directions of socio-economic development of the subjects of the Central Federal District of the Russian Federation, leading to sustainability, are substantiated, and methodological recommendations for its assessment are proposed.

Keywords: economic potential, regional development, strategic priority, expanded reproduction, inflation, per capita income, investment in fixed assets, competitive positions.
B опросы оценки социально-экономического развития регионов находят отражение в зарубежных и отечественных исследованиях. В этой связи интерес представляет выявление сущностных характеристик потенциала развития, определение показателей оценки конкурентных позиций, которые бы точно отражали механизм порождения хаоса и неопределённости в среде рынка.

Общеизвестно, что под социально-экономическим развитием понимается состояние национальной эко-
Щербаков Виктор Николаевич

Д.э.н., профессор, Финансовый университет при Правительстве РФ; в.н.С., Институт экономики РАН,

2. Москва

sherbakovvn@yandex.ru

Дубровский Андрей Викторович

К.э.н., дочент, Финансовый университет при

Правительстве РФ, г. Москва

dav-rgsu@yandex.ru

Аннотация. В статье выявлены закономерности социально-экономического развития субъектов как составляющих потенциала устойчивого роста региона, а также обоснованы методологические основы комплексной оценки и мониторинга конкурентных позиций регионов Центрального федерального округа РФ с точки зрения нахождения резервов устойчивого роста. Гипотеза исследования заключается в обосновании с учетом научного и практического опыта предположения, что оценка потенциала социально-экономического развития региона позволяет выявить направления повышения устойчивости хозяйственной системы и её конкурентных позиций.

Для оценки уровня развития регионов использован ряд экономических и социальных индикаторов. Расчет интегральных параметров экономического и социального развития осуществлялся посредством нормирования по среднероссийскому значению. Обоснованы приоритетные направления социально-экономического развития субъектов Центрального федерального округа РФ, приводящие к устойчивости, и предложены методические рекомендации по её оценке.

Ключевые слова: экономический потенциал, развитие регионов, стратегический приоритет, расширенное воспроизводство, инфляция, среднедушевые доходы, инвестиции в основной капитал, конкурентные позиции.

номики, определяемое рядом экономических и социальных показателей, при которых обеспечиваются экономический суверенитет страны, единство ее экономического пространства, условия для реализации стратегических национальных приоритетов страны. $[13$, c. 1190]

Заслуживает внимание и оценка социально-экономического развития с точки зрения наличия внутренней способности к самоорганизации хозяйствующего субъекта, к его устойчивому и эффективному функци- 


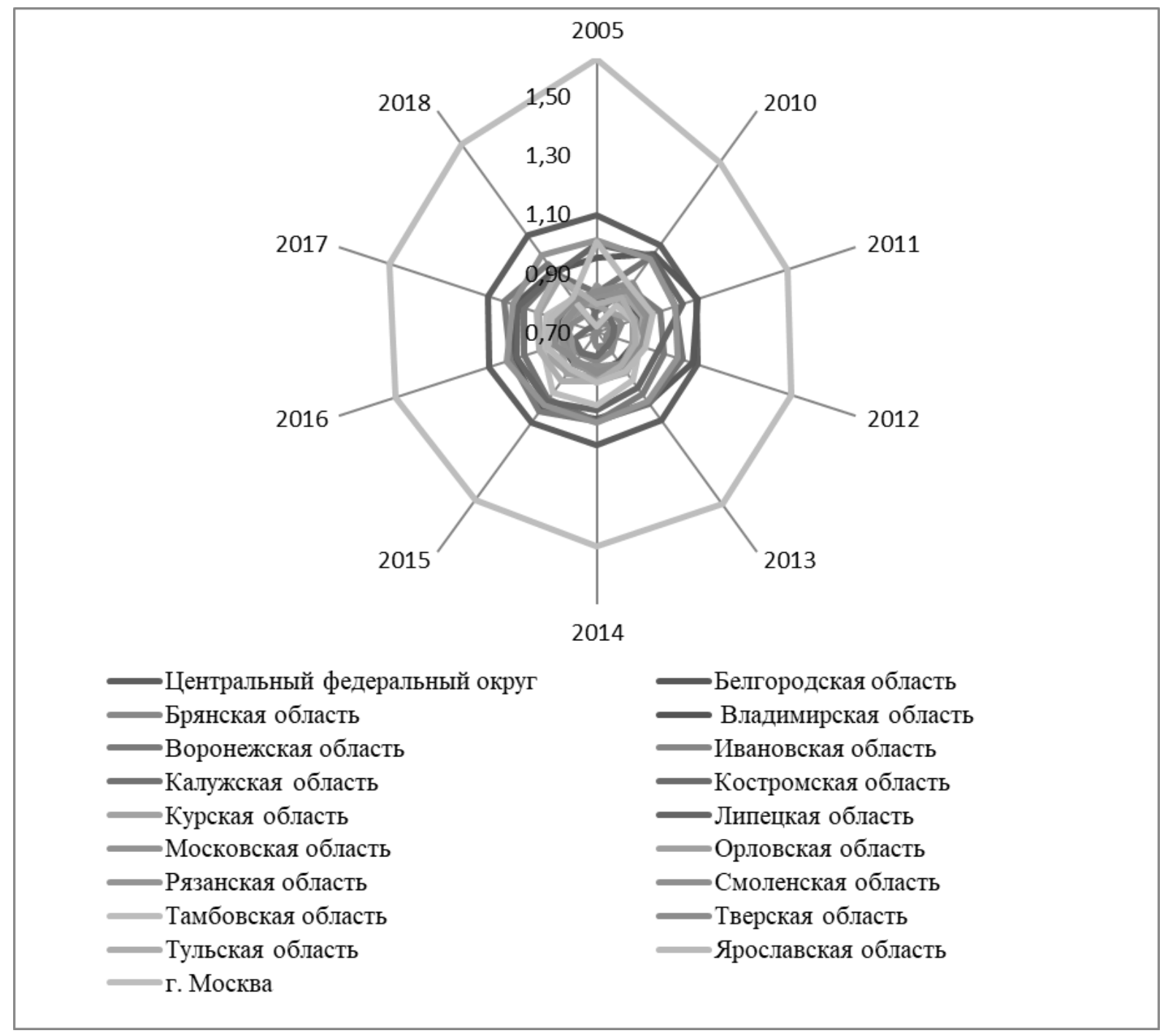

Рис. 1. Динамика интегрального коэффициента экономического потенциала 2005-2018 гг. Построено авторами на основании [10]

онированию и развитию. Если же определять экономическую устойчивость территории, то целесообразно отметить возможности поступательного развития, нейтрализации или ослабления экономических угроз и катастроф. Это связано с тем, что под воздействием продолжающихся санкций, границы которых не определены, происходит переосмысление интеграционных связей. Уходят на второй план концепты трактовок «рост без развития», т.е. масштабы спада в экономике требуют переосмысления ценности производства в потреблении и поиска качественных ориентиров в структурных преобразованиях тех отраслей, от которых зависит жизнеспособность страны в целом. [8, с. 20] Важно, в первую очередь подчеркнуть, что структурная политика должна поддерживать те отрасли и сектора экономики, которые обеспечивают рост и развитие с участием государства и под его контролем, а никак не наоборот. Это важно ещё и потому, что в России еще сохранился потенциал периода СССР, в частности В ВПК, ТЭК, транспортное машиностроение и т.д. [1, C. 157] В любой постановке значение эффективности, а значит и потенциала роста, будет определяться степенью конкурентоспособности отечественной экономики на основе роста технико-технологического и организационно-экономического потенциалов страны.

В настоящее время объявленный переход к новой цифровой парадигме роста вызывает большой и неоднозначный вопрос, связанный с тем, что в принятых стратегических программах нет механизма, способного активизировать потенциал социально-экономического развития, решить задачу безопасности отечественной экономики с точки зрения адаптация к новым вызовам. Ведь сущностная сторона устойчивости заключается 


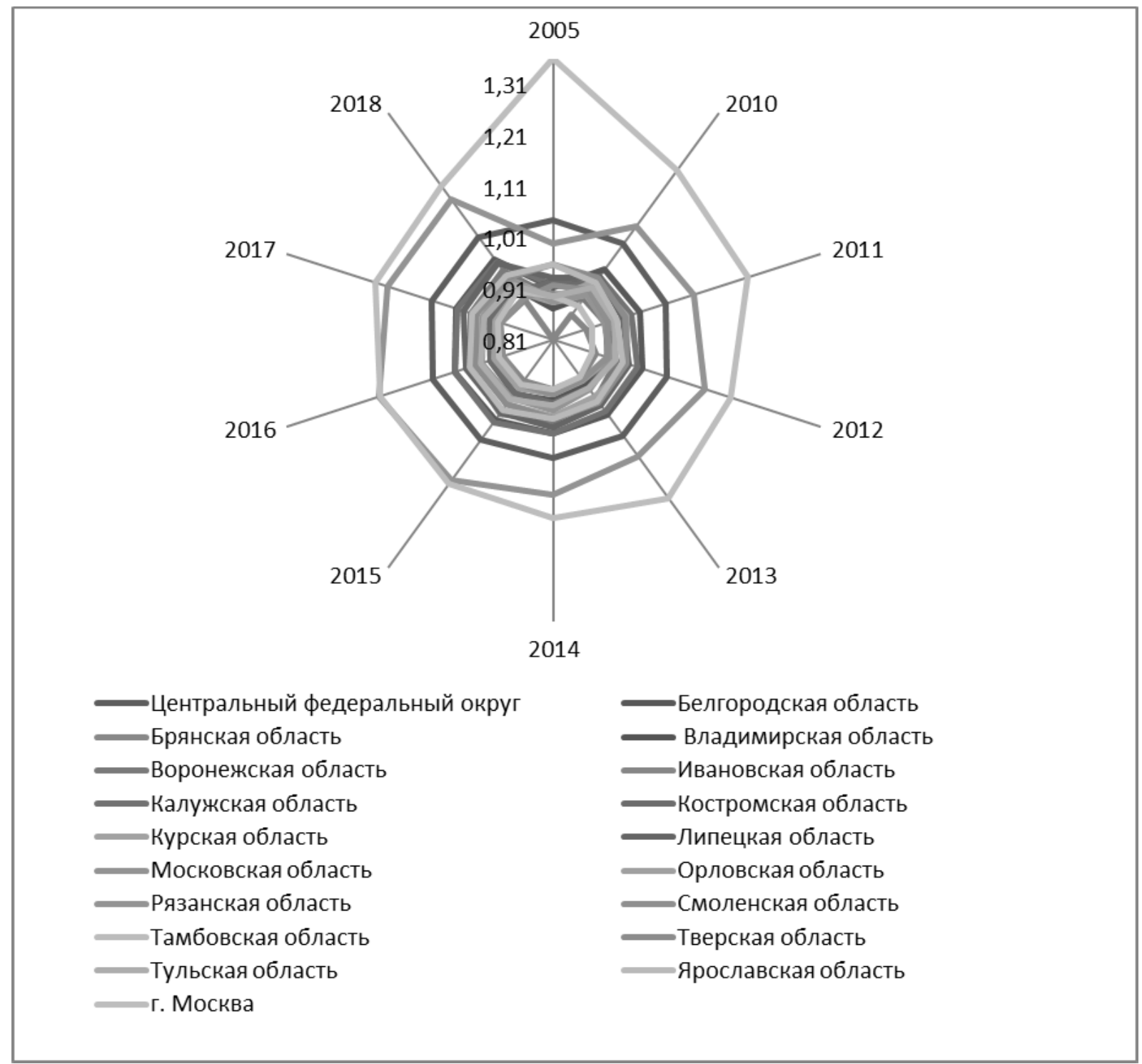

Рис. 2. Динамика коэффициента социального потенциала в 2000-2017 гг. Построено авторами на основании [10]

в качестве и стабильности жизни населения, гарантирующих мир и спокойствие в обществе; в возможности решать накопившиеся проблемы и активно влиять на острые социально-экономические вызовы, такие как негативы в демографических процессах, низкий жизненный уровень, высокая смертность, низкая рождаемость, снижение уровня человеческого потенциала. [3, с. 875]

Другими словами, постановка задачи должна состоять В том, чтобы базовой установкой при исследовании потенциала социально-экономического развития являлись национальные приоритеты, а не только экономическая целесообразность, всё более обостряющая ситуацию в социальной сфере и нарушающая жизненное пространство и привычный уклад страны.
Обращаясь к проблеме методологии и критериев оценки социально-экономического развития отметим, что в представленном исследовании для оценки его уровня были разработаны следующие интегральные показатели: коэффициент экономического потенциала (КЭП) и коэффициент социального потенциала (КСП). [4, с. 140] Используемый методологический подход предполагает применение среднедушевых показателей в интегральных коэффициентах. К показателям экономического потенциала (КЭП) были отнесены: годовой объем ВРП на душу населения, руб.; годовой уровень инфляции (индекс потребительских цен на товары и услуги - декабрь к декабрю), в\%; инвестиции в основной капитал, на душу населения, руб.; степень износа основных фондов (на конец года по полному кругу предприя- 

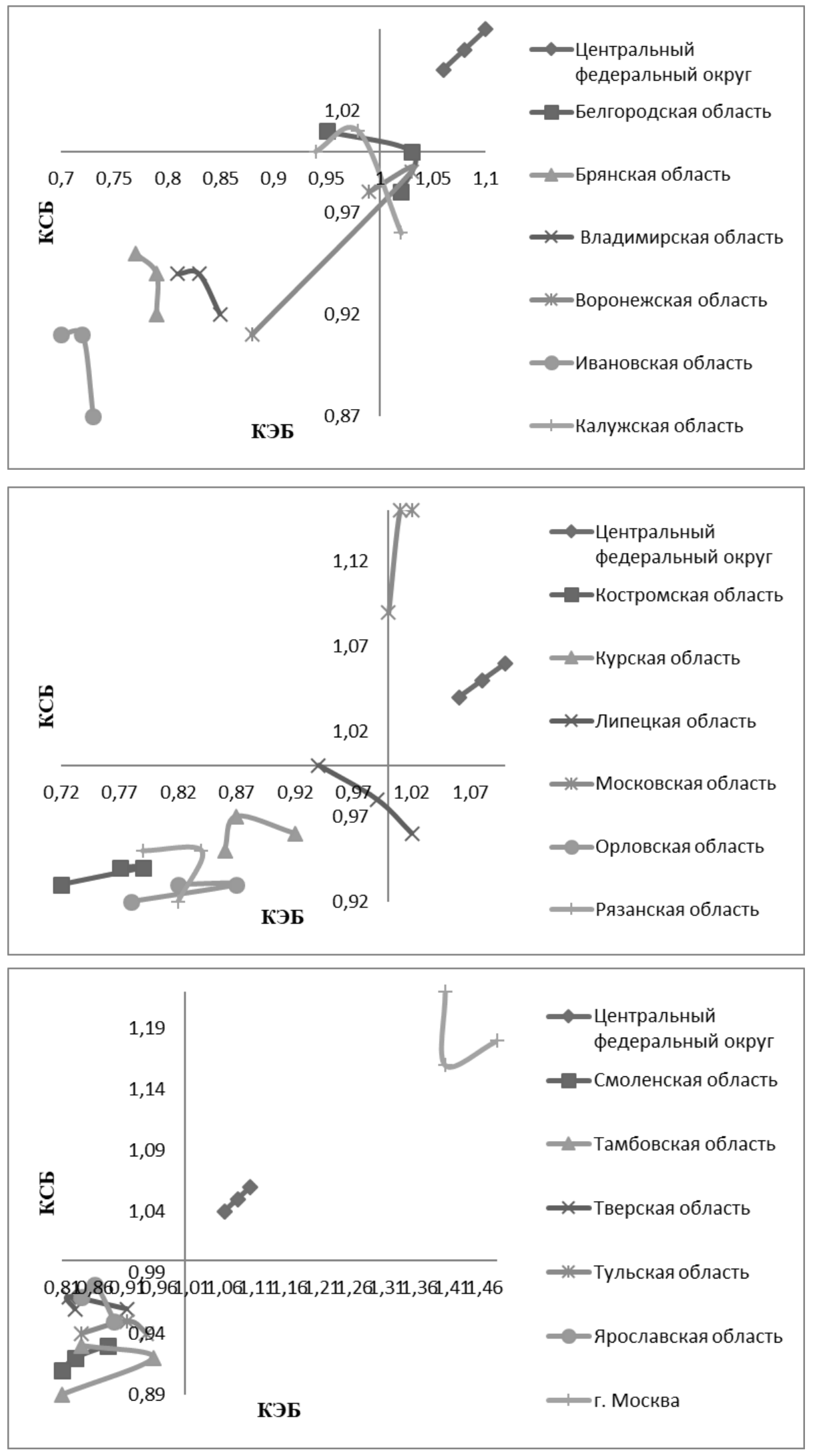

Рис. 3. Динамика показателей социально-экономического развития субъектов Центрального федерального округа в 2010-2018 гг.

Построено авторами на основании [10] 
тий), в\%; удельный вес убыточных организаций (на 1 января), в\%.

В качестве показателей, характеризующих социальный потенциал (КСП) были выбраны следующие: среднедушевые денежные доходы населения (в месяц, руб.); доля населения с денежными доходами ниже региональной величины прожиточного минимума в общей численности населения субъекта РФ, в процентах; средний размер назначенных пенсий, руб.; общая площадь жилых помещений, приходящаяся на одного жителя, кв. м; общий коэффициент рождаемости (число родившихся на 1000 чел населения).

Для расчета интегральных параметров экономического и социального развития все показатели были нормированы по среднероссийскому значению. Результатом стали графики рис. 1 и рис. 2, где проведены посчитанные средние показатели для группы экономических и социальных индикаторов.

На рис. 3 и в показано изменение показателей экономического и социального развития субъектов Центрального федерального макрорегиона РФ в 2010-2018 годах. Все рассматриваемые регионы были размещены на одной сетке и показана динамика средних значений КЭП и КСП, взятых за три года: 2010, 2015 и 2018.

Регионы, которые попали в правую верхнюю зону (первая четверть координатной плоскости) можно условно отнести к экономически и социально развитым.

Отмечаем, что два региона на протяжении рассматриваемого периода не покидали эту правую («безопасную») зону: г. Москва, Московская область. [15, с. 167] Именно их можно отнести к субъектам с высокими конкурентными позициями.

Белгородская область, Калужская область начинали за пределами «безопасной зоны», но со временем в нее входили. Белгородская область начинала в «безопасной зоне», но затем вышла из нее по экономическому развитию. Эти субъекты располагаются в зоне риска. Особую тревогу вызывает положение Ивановской, Брянской, Владимирской, Орловской, Костромской, Рязанской, Смоленской областей, которые не только заметно уступают, но и существенно отстают от ведущих регионов по экономическому и социальному потенциалу. Фактически она находится в состоянии затяжной рецессии.

Траектории регионов на рис. 3 показывают прогресс или регресс за рассматриваемый период с 2010-
2018 гг. как в экономическом, так и в социальном потенциале. Видно, что наибольшего прогресса в экономическом развитии добилась Москва и Московская область - они и обеспечивают рост конкурентных позиций в среднем по всему центральному федеральному округу. В социальном развитии добиться прогресса регионам гораздо сложнее.

Высокий уровень экономического развития Москвы, обеспечивается, прежде всего, за счет высокого ВРП на душу населения (превышение среднероссийского значения в 2,61 раза). Кроме того, в Москве ниже степень износа основных фондов (обратный показатель выше среднероссийского в 1,26 раза) и выше среднедушевой показатель инвестиций в основной капитал в 1,32 раза. $[7$, с. 10]

Высокое значение КСП Москвы обеспечиваются, прежде всего, высокими среднедушевыми доходами (выше среднероссийского в 2,2 раза), ростом показателя соотношением среднедушевых денежных доходов населения к прожиточному минимуму (выше среднероссийского в 1,04 раза), превышением среднероссийского уровня по показателю размера назначенных пенсий в 1,08 раза. При этом проблемными остаются показатели роста общей площади жилых помещений, приходящаяся в среднем на одного жителя (составляет 0,8 среднероссийского уровня) и коэффициент рождаемости, находящийся на уровне 0,88 от среднероссийского значения.

Сильными сторонами Московской области можно считать сравнительно низкий уровень износа основных фондов (износ основных фондов выше среднероссийского уровня в 1,12 раз) и удельный вес убыточных предприятий (обратный показатель выше среднероссийского в 1,02 раза). По оценке социального развития Московская область демонстрирует высокий уровень, превышая среднероссийский в 1,11 раза. Однако уровень неравенства доходов (коэффициент Джини - 393) выше среднего по округу в 1,07 раза), [2, с. 598] При этом уровень доходов населения по сравнению с Москвой невелик (отношение среднедушевых доходов составляло на 2018 год 1,53 раза, а уровень бедности немного выше - в 1,07 раза численность населения с доходами ниже прожиточного минимума меньше по сравнению в Москвой.

Московская область создает достаточно высокий ВРП, отдавая первенство только Москве (4201768,8 млн. руб. против 17881516,2 млн. руб. на 2018 год), предприятия активно обновляют основные фонды. При этом имеет целесообразность увеличение инвестиций в основной капитал. Уровень доходов населения относительно большой, уровень бедности ниже средне- 
российского, сравнительно низкое расслоение по доходам, безработица ниже среднероссийской.

Оценка интегральных показателей таких областей как Белгородская, Калужская, Воронежская, Курская, Тверская, Липецкая, Ярославская, Тульская, позволяет отнести их к достаточно развитым. Проанализируем источники роста этих областей.

Особенностью Белгородской области является достаточно высокий уровень ВРП на душу населения (его среднее значение соответствует среднему по стране) и низкий уровень износа фондов, превышающий среднероссийский в 1,07 раза, а также низкий удельный вес убыточных предприятий (обратный показатель в 1,05 выше среднероссийского). [11, с. 646] Это исключительно важно для экономики области и может играть роль потенциала роста.

Воронежская область не отличается большим объемом инвестиций в отличие от Липецкой области, где он составляет 1,06 от среднероссийского уровня. Это дает возможность активно генерировать добавленную стоимость в различных отраслях промышленности, транспортного комплекса, сельском хозяйстве, что достаточно хорошо видно по объему ВРП на душу населения - в Липецкой области он составляет 319842 руб. против 269350 руб. в Воронежской области

Оценка социально-экономических интегральных показателей таких областей как Брянская, Костромская, Владимирская, Смоленская, Орловская, Рязанская, Тамбовская, позволяет отнести их к слабо развитым. Проанализируем причины такого положения областей и источники роста.

Владимирская, Смоленская области создает относительно небольшой объем добавленной стоимости, чуть более на половину превышающих среднероссийский (среднедушевой ВРП составляет лишь 0,57 и 0,58 от среднего по стране значения соответственно). Предприятия не проявляют активности в привлечении инвестиций в основной капитал (среднедушевой показатель инвестиций в основной капитал составляют 0,51 и 0,64 от среднероссийского показателя в 1,07 раз). [14, c. 16] Организации Владимирской области более активно обновляют основные фонды по сравнению со Смоленской (обратный показатель степени износа фондов в 1,06 и 0,99 раз выше среднего по стране), при этом убыточность соответствует среднему по стране уровню).

Ивановская область генерирует относительно небольшой объем добавленной стоимости (душевой ВРП составляет 0,37 от среднего по стране), что обусловле- но низким уровнем инвестиций в основной капитал, составляющий 0,33 от среднероссийского. Уровень обновления основных фондов выше среднего (показатель составляет 1,07 от среднего по стране) что может определять потенциал роста в долгосрочной перспективе. Организации чаще среднего терпят убытки (обратный показатель доли убыточных организаций составляет 0,91 от среднего по стране). [5, с. 58]Эти параметры предопределяют достаточно низкий уровень экономического развития по интегральному коэффициенту - 0,73

В процессе исследования подтвердился тезис о том, что высокие доходы населения в регионе обуславливают более высокое расслоение, которое приводит к социальной напряжённости в регионе. Некоторые области демонстрируют высокие показатели социального развития, потому что там наблюдается так называемая «равномерная бедность», что характеризует отрицательную динамику регионального развития. Наблюдается следующая закономерность: чем ниже доходы, тем выше по отношению к ним пенсии. Это можно объяснить тем, что размер пенсии регулирует государство, а зарплаты - местный рынок труда. Фактически пенсии проходят инвариантной величиной через все регионы, со своими особенностями рынка труда и разным уровнем дохода.

В настоящее время становится вполне очевидным, что принятый механизм хозяйствования в Центральном федеральном округе не способствует повышению конкурентных позиций. [12, с. 599] Уровень социально-экономического развития тем ниже, чем ниже технико-технологический и организационный потенциалы, результатом чего является переход экономики в депрессивный или кризисный режим. Исследуя взаимосвязи экономического потенциала с точки зрения рациональности и эффективности, ряд предприятий центрального округа показывает, что в условиях архаичных производственных отношений основанных на механизмах рынка, очень высока вероятность перехода в кризисное состояние и депрессивный режим стагнирующего характера. [6, с. 911] Поэтому проблема повышения конкурентных позиций субъекта всегда связана с уровнем технико-технологического и организационно-экономического потенциала, поддержание которого обеспечивает конкурентоспособность хозяйственного комплекса в экономической среде рынка и его поступательное развитие.

Результаты проведенного исследования убеждают в том, что в формирование в России модели устойчивого социально-экономического развития требует разработки механизмов рационального использования социально-экономического потенциала регионов как фактора управления в глобальном пространстве. 


\section{ЛИТЕРАТУРА}

1. Дубровский, А.В. Проблемы и перспективы экономического развития России в контексте либеральных преобразований / А.В. Дубровский // Экономика и предпринимательство -2020.— № 2 (115). — С. 151-158

2. Дубровский, А.В. Противоречия технологических и социально-экономических трансформаций в современной России / А.В. Дубровский, В.Н. Щербаков // Самоуправление -2021. - № 2.(124) - С. 596-600

3. Дубровский, А.В. Формирование современной парадигмы устойчивого экономического развития / А.В. Дубровский // Экономика и предпринимательств0 -2020 . — № 3(116). - С. 872-877

4. Зубаревич, Н.В. Стратегия пространственного развития: приоритеты и инструменты / Н.В. Зубаревич // Вопросы экономики. - 2019 - № 1. C. 135-145.

5. Макарова, И.В. Система приоритетов развития России. / И.В. Макарова // Научно-аналитический журнал «Актуальные проблемы социально-экономического развития России».— 2014.— № 1.- С. 57-60

6. Пасикун, В.Н. Методологические проблемы оценки эффективности инвестиционных проектов в промышленности / В.Н. Пасикун, А.В. Дубровский // Экономика и предпринимательств0. - 2015. — № 12-3 (65). - С. 909-912

7. Самсонов, К.В. Варианты инновационного развития промышленности / К.В. Самсонов, В.Н. Щербаков, А.В. Дубровский // Актуальные проблемы социально-экономического развития России. - 2013. - № 4. - С. 9-12

8. Сорокин, Д.Е. Политическая экономия технологической модернизации России / Д.Е. Сорокин // Экономическое возрождение России.- 2020.№ 1(63). - C. 18-25

9. Указ президента РФ «0 стратегии экономической безопасности РФ на период до 2030 года» http://publication.pravo.gov.ru/Document/ View/0001201705150001

10. Федеральная служба государственной статистики http://www.gks.ru

11. Щербаков, В.Н. Модернизация экономики и проблемы эффективности / В.Н. Щербаков, А.В. Дубровский // Самоуправление -2020. 一 Т. 2, № 2.(119) - C. 633-647

12. Щербаков, В.Н. Противоречия технологических и социально-экономических трансформаций в современной России / В.Н. Щербаков, А.В. Дубровский // Самоуправление -2021. — № 2.(124) - C. 596-600

13. Щербаков, В.Н. Совершенствование интеграционных связей бизнеса и государства в стратегии модернизации промышленности / В.Н. Щербаков, А.В. Дубровский// Экономика и предпринимательство. - 2016. — № 12-2 (77-2). — С. 1188-1192.

14. Щербаков, В.Н. Управление рисками инновационно-инвестиционной деятельности предприятия / В.Н. Щербаков, А.В. Дубровский, А.С. Тотанов // Актуальные проблемы социально-экономического развития России. - 2013. - № 4. - C. 13-16

15. Экономико-теоретические исследования в финансовом университете: история и современность. Монография / В.П. Акугинова, Ю.И. Будович, А.В. Дубровский [и др.] - М.: 000 «Русайнс», 2021.-272с. 